\title{
Barriers to utilization of antenatal care services in eastern Nepal
}

\section{Krishna Kumar Deo ${ }^{1 t}$, Yuba Raj Paudel ${ }^{2 * t}$, Resham Bahadur Khatri ${ }^{3 t,}$ Ravi Kumar Bhaskar ${ }^{4}$, Rajan Paudel ${ }^{5}$, Suresh Mehata ${ }^{2}$ and Rajendra Raj Wagle ${ }^{5}$}

\begin{abstract}
Karuna Foundation Nepal, Kathmandu, Nepal, ${ }^{2}$ Nepal Health Sector Support Program, Ministry of Health and Population, Kathmandu, Nepal, ${ }^{3}$ Saving Newborn Lives Program, Save the Children, Kathmandu, Nepal, ${ }^{4}$ Department of Community Medicine and Public Health, National Medical College, Birgunj, Nepal, ${ }^{5}$ Department of Community Medicine and Public Health, Institute of Medicine, Tribhuwan University, Kathmandu, Nepal
\end{abstract}

\section{OPEN ACCESS}

Edited by:

Joao Soares Martins,

Universidade Nacional Timor

Lorosa'e, Timor-Leste

Reviewed by:

Hsien-Chang Lin,

Indiana University, USA

Marisa Theresa Gilles,

Western Australian Country Health

Service, Australia

*Correspondence:

Yuba Raj Paudel,

Nepal Health Sector Support Program, Family Health Division, GPO Box 7830, Teku, Kathmandu,

Nepal

yubaraj.paude/@gmail.com

${ }^{\dagger}$ Krishna Kumar Deo,

Yuba Raj Paudel and

Resham Bahadur Khatri have contributed equally to this work.

Specialty section: This article was submitted to Public Health Policy, a section of the journal Frontiers in Public Health

Received: 28 March 2015 Accepted: 29 July 2015 Published: 14 August 2015

Citation:

Deo KK, Paudel YR, Khatri RB, Bhaskar RK, Paudel R, Mehata S and Wagle RR (2015) Barriers to utilization

of antenatal care services in eastern Nepal.

Front. Public Health 3:197. doi: 10.3389/fpubh.2015.00197
Background: World Health Organization recommends at least four pregnancy checkups for normal pregnancies. Ministry of Health and Population Nepal has introduced various strategies to promote prenatal care and institutional delivery to reduce maternal and child deaths. However, maternal health service utilization is low in some selected socio-economic and ethnic groups. Hence, this study aims to assess barriers to the recommended four antenatal care (4ANC) visits in eastern Nepal.

Methods: A cross-sectional quantitative study was conducted in Sunsari district. A total of 372 randomly selected women who delivered in the last year preceding the survey were interviewed using a semi-structured questionnaire. Bivariate and multivariate logistic regression analysis was carried out to identify barriers associated with 4ANC visits.

Results: More than two-third women (69\%) attended at least 4ANC visits. The study revealed that women exposed to media had higher chance of receiving four or more ANC visits with an adjusted odds ratio $(\mathrm{aOR}=3.5,95 \% \mathrm{Cl}: 1.2-10.1)$ in comparison to women who did not. Women from an advantaged ethnic group had more chance of having 4ANC visits than respondents from a disadvantaged ethnic group (aOR $=2.4,95 \%$ Cl: 2.1-6.9). Similarly, women having a higher level of autonomy were nearly three times more likely (aOR $=2.9,95 \% \mathrm{Cl}: 1.5-5.6)$ and richer women were twice $(\mathrm{aOR}=2.3,95 \%$ Cl: 1.1-5.3) as likely to have at least 4 ANC visits compared to women who had a lower level of autonomy and were economically poor.

Conclusion: Being from disadvantaged ethnicity, lower women's autonomy, poor knowledge of maternal health service and incentive upon completion of ANC, less media exposure related to maternal health service, and lower wealth rank were significantly associated with fewer than the recommended 4ANC visits. Thus, maternal health programs need to address such socio-cultural barriers for effective health care utilization.

Keywords: four antenatal care visits, socio-cultural factors, utilization, Nepal 


\section{Introduction}

Evidence suggests that most maternal deaths and pregnancyrelated complications can be prevented if pregnant women have access to good quality maternal health services, which include focused care during pregnancy, care around delivery, and immediate post-partum care (1-3). For women with normal pregnancies, World Health Organization (WHO) recommends a minimum of four antenatal care (ANC) visits, ideally at 16, 24-28, 32, and 36 weeks (4). ANC offers an important opportunity for healthcare providers to detect, treat, and prevent pregnancy-related problems and many life-threatening conditions (5). Further, ANC visit helps in timely referral to the appropriate health facilities; ensures birth preparedness and complication readiness for both normal and obstetric emergencies; and provides tetanus toxoid (TT) immunization, iron tablets, de-worming tablets to all pregnant women, and malaria prophylaxis where necessary $(6,7)$.

Ministry of Health and Population (MoHP) Nepal has been providing maternal and child health services including ANC check-ups from the health system network extended up to the community level (8). To increase demand for and improve access to maternity services, MOHP launched maternity incentives scheme in 2005 to provide each woman a fixed amount of money to cover transportation costs, based on ecological region (9). Further, 4ANC incentive was introduced in 2009 to promote antenatal services along with institutional delivery (9). However, many studies have shown effectiveness of these incentives and thereby utilization of maternal health services has been low by many poor and excluded groups (10-14).

Although substantial improvement was observed over the last decade, Nepal still has high maternal mortality ratio (MMR) compared to many developed countries (15). According to a survey conducted in 2008/09, the MMR in Nepal was estimated to be 229 per 100,000 live births, which accounted for $11 \%$ of all deaths among women of reproductive age (15-49 years) (16). Despite ongoing efforts to promote maternal health service utilization, wide disparities prevail among women residing in rural parts and belonging to the lowest wealth quintiles, and from ethnic minorities (17).

Growing body of research suggests that along with supply-side and demand-side factors including individual and household factors, socio-cultural factors, such as women's autonomy (18), caste/ethnicity, religion and belief (19), women's media exposure regarding pregnancy and health care (20), influence health seeking behavior. Further, socio-cultural factors are contextual and entrenched (21) and amplify geographical and financial barriers experienced by women to access maternal health services (22). Many studies have documented poor utilization of institutional delivery by Terai's (Plain region) Muslims and Dalits $(23,24)$. A qualitative study conducted in Nepal showed that pregnant women's heavy work-load, women-in-law's perception of benefit of ANC, her power and control over resources, and relationship between mother-in-law and pregnant women played a vital role in pregnant women's utilization of ANC (25). However, role of socio-cultural factors including ethnicity, women's status, education, exposure to media, and others in relation to demographic and economic factors in utilization of antenatal service remain under-investigated in Nepal. Few of the previously conducted studies in Nepal have included women delivered in last 24 months or more as study participants, rendering findings prone to recall bias $(26,27)$. In addition, since attending $4 \mathrm{ANC}$ visits was found to be positively associated with SBA utilization (28), investigating barriers to $4 \mathrm{ANC}$ visits will provide evidence for promoting delivery by skilled providers. Therefore, this study aims to identify factors associated with utilization of $4 \mathrm{ANC}$ visits among women who delivered within last 12 months of preceding the survey from three Village Development committees (VDC) of Sunsari district.

\section{Materials and Methods}

\section{Study Setting and Participants}

A cross-sectional quantitative study was conducted in three VDCs: Haripur, Shreepur, and Kushaha of Sunsari district of eastern Nepal. The VDCs are located within $25-32 \mathrm{~km}$ south from district headquarters at Inaruwa. The VDCs were selected due to the first author's familiarity and having a good mix of ethnic groups since the study focused on assessing socio-cultural factors associated with service utilization. Women who had delivered within a 1-year period preceding this study and gave informed consent were interviewed. Sub Health Posts (SHPs), which are the government health institutions within the VDCs, were consulted to get lists of mothers of children born and immunized during last 1 year period. Since, BCG coverage of the selected VDCs was almost $100 \%$ of the target provided by Department of Health Services, Nepal, all mothers who delivered in last 12 months are assumed to be included in sampling frame.

\section{Sampling and Sample Size}

Sample size was calculated by using the formula: $N=1.962 p q / L^{2}$ where $p$ is the prevalence of institutional delivery (35.5\%) from Nepal Demographic and Health Survey (NDHS) 2011 (17). The final sample size was estimated to be 387 considering $5 \%$ allowable error and assuming 10\% possible non-response. A list of households was prepared to trace households with mothers of children aged under 1 year. A total of 387 households out of 1064 were selected by systematic random sampling method. A total of 15 mothers could not be met during household visit; hence, 372 mothers were included in current analysis.

\section{Data Collection}

Pretesting of questionnaire was carried out in households of adjoining VDC, and necessary modifications were made. The questionnaire was originally prepared in English then translated into the local language of the study area, i.e., Maithili. Enumerators were trained before data collection. Data collection was carried out from July to August 2012. From these households, women who delivered within a period of 1 year preceding this study were interviewed through a household visit using a structured questionnaire. In non-response cases, mother from another immediate household was interviewed. The first author himself was involved in data collection process and supervision of enumerators.

Data checking, editing, and coding were done by the researcher each day. Data entry was done in Epi Data 3, and analysis was carried out in Statistical Package for Social Science (SPSS) 17. 


\section{Outcome Variable}

Information about $4 \mathrm{ANC}$ visits was determined by asking "How many times did you visit a health facility for ANC check-up?" And the number of reported visits was categorized into two categories: women who make at least $4 \mathrm{ANC}$ were coded as 1 , and women who did not make any visits or made $<4$ visits were coded as 0 .

\section{Explanatory Variables}

Altogether, 19 explanatory variables were included in the analysis to assess their association with 4ANC visits based on previous studies in developing countries as well as from researchers' knowledge on the subject. Most of the selected variables were nominal and few variables, such as wealth quintile, age, women's autonomy, and knowledge of maternal health services, educational level were categorized into ordinal scales. The variables include socio-demographic and cultural variables including age, caste/ethnicity, religion, education of respondent, education of husband, occupation of respondent, occupation of husband, wealth quintile and women's autonomy; knowledge, belief, and exposure-related variables including exposure to media, frequency of exposure, contact with Female Community Health Volunteers (FCHVs), frequency of contact with FCHVs, sex of previous child, belief in traditional healer's practice, knowledge of maternal health services and knowledge of transport incentives on completion of 4ANC, institutional delivery, and first postnatal care (PNC) visit; and biological variables including parity and experience of pregnancy complications in recent pregnancy. Educational level of respondent and her husband was categorized into two category ordinal scale: literate, which includes primary and above qualification and those who can read and write by attending adult literacy class, and illiterate includes never gone to school and unable to read and write.

Similarly, wealth quintile and wealth rank were categorized using principle component analysis of household assets and expenditures. The first and second quartiles were categorized as low (poor), and third and fourth were categorized as high (rich) wealth rank. The ethnicity status of mother was categorized into two categories: disadvantaged includes Dalit and Muslim and relatively advantaged ethnicity includes non-Dalit and advantaged Terai castes, Janjati, and upper caste group. Women's autonomy was measured by analyzing three key areas: control over finances, decision-making power and the extent to which they have freedom of movement using 10 variables, and households were categorized into three groups using factor analysis from low autonomy to high autonomy. Factor analysis was used to create a female autonomy score, which was divided into terciles. It was further categorized on two ranks, low and high, while carrying out analysis. Exposure to media was categorized into yes or no. The respondents were asked whether they were exposed to any mass media including print, radio, and television depicting information regarding ANC visits and institutional delivery and PNC visits during her last pregnancy.

\section{Statistical Analysis}

Bivariate association of independent variables and 4ANC was examined using Chi-square test. A multivariate logistic regression model was developed for the characteristics that were significant in Chi-square test $(p<0.1)$. Stepwise backward elimination process was used in multivariate logistic regression. A $p$ value of $<0.05$ using Chi-square test was considered significant in the final model.

\section{Research Ethics}

This study got ethical approval from Institutional Review Board of Institute of Medicine, Maharajgunj Medical Campus, Tribhuwan University, Kathmandu, Nepal. The interviewers explained the research objectives to the participants before starting the interview. Participants were clearly explained about their right to withdraw from the interview at any time. Personal identifiers were removed before analysis.

\section{Results}

\section{Characteristics of Participants}

More than three-quarters of the women (77\%) were Hindu. Most of the mothers were multiparous (72\%), while more than $6 \%$ of women became a mother below the age of 20 years. Nearly half (48\%) of the respondents were from disadvantaged ethnic group. More than 9 in 10 (94\%) women were literate. About 60\% mothers had information on availability of free-delivery service, while about $69 \%$ mothers had information on transportation incentive on utilization of institutional delivery service. About two in five (37\%) mothers had experienced obstetric complications in their recent pregnancy (Tables $\mathbf{1}$ and 2).

\section{Prevalence of 4ANC Coverage}

Among 372 respondents, 257 (69\%) women received at least ANC visits, while 49 (13\%) women received no ANC visits (Table 3). The coverage of $4 \mathrm{ANC}$ among women from advantaged ethnic group was higher $(84 \%)$ than those from disadvantaged ethnic group (53\%). Similarly, women from the richest family were more (85\%) likely to attend $4 \mathrm{ANC}$ check-ups in comparison to women from poorest economic background (50\%). Women who have higher level of autonomy (83\%) in comparison to lower level of autonomy (54\%), mothers who were exposed to media (83\%) had higher likelihood of $4 \mathrm{ANC}$ visits compared to those who were not exposed to media (52\%). Those who had knowledge on transportation incentive (90\%) had higher 4ANC coverage than those who did not have knowledge of incentives (52\%) (Tables 1 and 2).

\section{Factors Associated to Utilization of Antenatal Care Services}

In bivariate analysis, a number of variables, such as ethnicity, religion, education status of husband, wealth quintile of the family, women autonomy, media exposure, knowledge on maternal health and transportation incentive, showed statistically significant association in 4ANC service utilization (Tables 1 and 2). Multivariate logistic regression showed that women from advantaged ethnicity ( $\mathrm{aOR}=2.4,95 \% \mathrm{CI}: 2.1-6.9)$, having higher level of autonomy $(\mathrm{aOR}=2.9,95 \% \mathrm{CI}: 1.5-5.7)$ and women from higher wealth quintile $(\mathrm{aOR}=2.3,95 \% \mathrm{CI}$ : 1.1-5.3) had higher chance of using at least $4 \mathrm{ANC}$ services compared to women who were from disadvantaged ethnic groups, women who have low level of autonomy, and women from poor families, respectively. 
TABLE 1 | Socio-demographic variables and utilization of ANC services.

\begin{tabular}{|c|c|c|c|c|}
\hline Variables & Total $n(\%)^{a}$ & $<4$ ANC (\%) & $\geq 4$ ANC $(\%)^{b}$ & $p$ Value \\
\hline \multicolumn{5}{|c|}{ Age group of respondents } \\
\hline$<20$ & $23(6.2)$ & 26.09 & 73.91 & \multirow[t]{4}{*}{0.42} \\
\hline $20-24$ & $165(44.3)$ & 34.55 & 65.45 & \\
\hline $25-29$ & $102(27.4)$ & 33.34 & 66.66 & \\
\hline 30 or above & $82(22.0)$ & 21.36 & 78.64 & \\
\hline \multicolumn{5}{|l|}{ Caste/ethnicity } \\
\hline Disadvantaged & $179(48.1)$ & 46.93 & 53.07 & \multirow[t]{2}{*}{0.001} \\
\hline Relatively advantaged & $193(51.9)$ & 16.06 & 83.94 & \\
\hline \multicolumn{5}{|l|}{ Religion } \\
\hline Hindu & $287(77.1)$ & 24.04 & 75.96 & \multirow[t]{2}{*}{0.001} \\
\hline Muslim & 85 (22.9) & 54.12 & 45.88 & \\
\hline \multicolumn{5}{|c|}{ Education of respondent } \\
\hline Illiterate & $23(6.2)$ & 43.48 & 56.52 & \multirow[t]{2}{*}{0.178} \\
\hline Literate & 349 (93.9) & 30.09 & 69.91 & \\
\hline \multicolumn{5}{|l|}{ Education of husband } \\
\hline Illiterate & $38(10.2)$ & 50 & 50 & \multirow[t]{2}{*}{0.007} \\
\hline Literate & $334(89.8)$ & 28.74 & 71.26 & \\
\hline \multicolumn{5}{|c|}{ Occupation of respondent } \\
\hline Service/business & 47 (12.6) & 31.91 & 68.09 & \multirow[t]{2}{*}{0.874} \\
\hline Agriculture/wage labor & $325(87.4)$ & 30.77 & 69.23 & \\
\hline \multicolumn{5}{|l|}{ Parity } \\
\hline Primiparous & $103(27.7)$ & 24.28 & 75.72 & \multirow[t]{2}{*}{0.08} \\
\hline Multiparous & $269(72.3)$ & 33.46 & 66.54 & \\
\hline \multicolumn{5}{|c|}{ Occupation of husband } \\
\hline Service/business & $161(43.3)$ & 29.81 & 70.19 & \multirow[t]{2}{*}{0.88} \\
\hline Agriculture/wage & $211(56.7)$ & 31.75 & 68.25 & \\
\hline \multicolumn{5}{|l|}{ Wealth quintile } \\
\hline First (poor) & $74(19.9)$ & 50 & 50 & \multirow[t]{5}{*}{0.001} \\
\hline Second & $75(20.2)$ & 38.67 & 61.33 & \\
\hline Third & $69(18.5)$ & 28.99 & 71.01 & \\
\hline Fourth & $80(21.5)$ & 22.5 & 77.5 & \\
\hline Fifth (rich) & $74(19.9)$ & 14.86 & 85.14 & \\
\hline \multicolumn{5}{|l|}{ Women's autonomy } \\
\hline Low & 125 (33.6) & 45.6 & 54.4 & \multirow[t]{4}{*}{0.006} \\
\hline Medium & $132(35.5)$ & 28.79 & 71.21 & \\
\hline Higher & $115(30.9)$ & 17.39 & 82.61 & \\
\hline Total & 372 & 31.0 & 69.0 & \\
\hline
\end{tabular}

${ }^{a}$ Values in parentheses indicate $\%$ of total $(n=372)$

Indicates row percentage.

Indicates Chi-square test of association between $4 A N C$ and other group.

Bold font indicates "significantly associated at $p<0.05$ ".

Similarly, women with good knowledge of maternal health services $(\mathrm{aOR}=5.4,95 \% \mathrm{CI}: 1.3-23.3)$ and women exposed to media (aOR $=3.5,95 \% \mathrm{CI}: 1.2-10.1$ ) were more likely to have four or more ANC visits than the women having poor knowledge and women who were not exposed to media information regarding maternal health care (Table 4). In addition, women who believed in traditional healers were less likely ( $\mathrm{aOR}=0.0595 \%$ CI: $0.01-0.26)$ to attend $4 \mathrm{ANC}$ service compared to women who did not believe in traditional healers.

\section{Discussion}

This study showed a higher prevalence (69\%) of 4ANC visits than other recent national studies $(17,29)$. However, NDHS 2011 also showed higher proportion of women from eastern Terai region to have received ANC in comparison to women from mountain or hill ecological regions. Furthermore, proportion of literate and young women was high among current study participants compared to
TABLE 2 | Knowledge, exposure, and utilization of ANC services.

\begin{tabular}{|c|c|c|c|c|}
\hline Variables & Total $n(\%)^{\mathrm{a}}$ & $<$ 4ANC (\%) & $\geq 4$ ANC $(\%)^{b}$ & $p$ Value $^{c}$ \\
\hline \multicolumn{5}{|l|}{ Media exposure } \\
\hline No & $170(45.7)$ & 47.65 & 52.35 & 0.001 \\
\hline Yes & $202(54.3)$ & 16.83 & 83.17 & \\
\hline \multicolumn{5}{|l|}{ Frequency of media } \\
\hline At least once a week & $185(49.7)$ & 20.54 & 79.46 & 0.001 \\
\hline Less than once a week & 59 (15.9) & 42.37 & 57.63 & \\
\hline \multicolumn{5}{|l|}{ Contact with FCHVs } \\
\hline No & $124(33.3)$ & 47.58 & 52.42 & 0.001 \\
\hline Yes & $248(66.7)$ & 22.58 & 77.42 & \\
\hline \multicolumn{5}{|l|}{$\begin{array}{l}\text { Frequency of contact } \\
\text { with FCHVs }\end{array}$} \\
\hline One time & $136(36.6)$ & 31.62 & 68.38 & $<0.001$ \\
\hline Two or more time & 114 (30.6) & 11.40 & 88.6 & \\
\hline \multicolumn{5}{|l|}{$\begin{array}{l}\text { Pregnancy/obstetric } \\
\text { complication }\end{array}$} \\
\hline No & $233(62.6)$ & 32.62 & 67.38 & 0.357 \\
\hline Yes & $139(37.4)$ & 28.06 & 71.94 & \\
\hline \multicolumn{5}{|l|}{ Sex of previous child } \\
\hline Male & 145 (38.9) & 33.79 & 66.21 & 0.991 \\
\hline Female & 148 (39.8) & 33.78 & 66.22 & \\
\hline \multicolumn{5}{|l|}{$\begin{array}{l}\text { Belief in traditional } \\
\text { healer's practices }\end{array}$} \\
\hline No & $140(37.6)$ & 11.43 & 88.57 & 0.001 \\
\hline Yes & $232(62.4)$ & 42.67 & 57.33 & \\
\hline \multicolumn{5}{|c|}{$\begin{array}{l}\text { Knowledge on maternal } \\
\text { health services }\end{array}$} \\
\hline Poor & 109 (29.3) & 56.88 & 43.12 & 0.001 \\
\hline Medium & $125(33.6)$ & 35.20 & 64.8 & \\
\hline High & $138(37.1)$ & 6.52 & 93.48 & \\
\hline \multicolumn{5}{|c|}{$\begin{array}{l}\text { Knowledge on } \\
\text { transportation incentive }\end{array}$} \\
\hline No & $208(55.9)$ & 47.60 & 52.4 & $<0.001$ \\
\hline Yes & $164(44.1)$ & 9.76 & 90.24 & \\
\hline Total & 372 & 31.0 & 69.0 & \\
\hline
\end{tabular}

${ }^{a}$ Values in parentheses indicate \% of total $(n=372)$.

Indicates row percentage.

cIndicates Chi-square test of association between $4 A N C$ and other group.

Bold font indicates "significantly associated at $p<0.05$ ".

TABLE 3 | utilization of ANC services.

\begin{tabular}{lcc}
\hline ANC visit (times) & Number & Percentage \\
\hline 0 & 49 & 13.2 \\
$1-3$ & 66 & 17.7 \\
$\geq 4$ ANC & 257 & 69.1 \\
\hline
\end{tabular}

participants from earlier studies (17), since educational level was found to be strongly associated with ANC utilization (28). Less distance to nearest health facility ( $78 \%$ households within $30 \mathrm{~min}$ distance from nearest health post in rural eastern Terai compared to $62 \%$ nationally) (30), and easy access to transportation in Terai region might have resulted in higher coverage of $4 \mathrm{ANC}$ in current study. A previous study concluded that $<30$ min distance from nearest health facility was positively associated with higher coverage of ANC visit (28).

Women from advantaged ethnic groups (84\%), rich (85\%), and having higher autonomy (83\%) status had higher chance of getting $4 \mathrm{ANC}$ services. These findings are similar to other studies conducted in developing countries $(31,32)$. A study conducted in Nepal also showed that women from rich family have three times 
TABLE 4 | Multivariate logistic regression analysis of factors associated with 4ANC visits.

\begin{tabular}{|c|c|c|}
\hline Variables & Crude OR (95\% Cl) & Adjusted OR (95\% Cl) \\
\hline \multicolumn{3}{|l|}{ Caste/ethnicity } \\
\hline Disadvantaged & 1 & 1 \\
\hline Relatively advantaged & $4.62(2.84-7.44)$ & $2.43(2.04-6.92)^{*}$ \\
\hline \multicolumn{3}{|l|}{ Women's autonomy } \\
\hline Low & 1 & 1 \\
\hline High & $3.12(2.18-7.2)$ & $2.86(1.47-5.64)^{\star}$ \\
\hline \multicolumn{3}{|l|}{ Wealth rank } \\
\hline Low (poor) & 1 & 1 \\
\hline High (rich) & $2.45(1.27-4.8)$ & $2.28(1.06-5.25)^{\star}$ \\
\hline \multicolumn{3}{|l|}{ Media exposure } \\
\hline No & 1 & 1 \\
\hline Yes & $4.17(2.72-7.77)$ & $3.48(1.20-10.05)^{\star}$ \\
\hline \multicolumn{3}{|c|}{ Frequency of media exposure } \\
\hline At least once a week & 1 & 1 \\
\hline Less than once a week & $0.35(0.18-0.65)$ & $0.75(0.26-2.16)$ \\
\hline \multicolumn{3}{|l|}{ Contact with FCHVs } \\
\hline No & 1 & 1 \\
\hline Yes & $3.11(1.75-4.72)$ & $0.72(0.51-2.14)$ \\
\hline \multicolumn{3}{|c|}{$\begin{array}{l}\text { Knowledge on maternal } \\
\text { health }\end{array}$} \\
\hline Poor & 1 & 1 \\
\hline High & $18.4(8.17-41.3)$ & $5.44(1.26-23.33)^{\star}$ \\
\hline \multicolumn{3}{|c|}{$\begin{array}{l}\text { Knowledge on incentive } \\
\text { upon completion of } 4 \text { ANC }\end{array}$} \\
\hline No & 1 & 1 \\
\hline Yes & $8.40(4.66-15.8)$ & $4.85(1.45-16.14)^{\star}$ \\
\hline \multicolumn{3}{|l|}{$\begin{array}{l}\text { Belief in traditional } \\
\text { healer's practices }\end{array}$} \\
\hline No & 1 & 1 \\
\hline Yes & $0.17(0.09-0.30)$ & $0.05(0.01-0.26)^{*}$ \\
\hline
\end{tabular}

*Statistically significant at $p<0.5$ level of confidence and adjusted for all other variables in the table.

more chances of having $4 \mathrm{ANC}$ visit compared to women from poor family (14). Improvement in women's status and decisionmaking power regarding their health in rich and advantaged ethnicity, in comparison to poor and disadvantaged ethnicity, could have contributed to the higher $4 \mathrm{ANC}$ visit in these groups. Furthermore, access to financial resources, freedom of movement could have enabled these women to utilize antenatal services frequently (33). Women from advantaged ethnicities and rich families are also more likely to have been exposed to media, such as TV, which was reported to be associated with higher uptake of ANC in a previously conducted study in Nepal (19). In addition, women-in-laws from well-off families are more likely to see benefits of utilizing ANC care and encourage daughter-in-laws to utilize it (25). Higher autonomy through better decision-making power might have enabled pregnant women to complete ANC visits even by resisting discouragement from older women and mother in-laws (34). A previous study conducted in Nepal (35) showed women's higher autonomy to be associated with higher decision-making power including decision on health care use.

In our study, wealth rank was found to be associated with $4 \mathrm{ANC}$ visit. Rich women were two times more likely to complete $4 \mathrm{ANC}$ visit than poor women. Economic status is linked with access to many services. Moreover, health service is generally linked with cost. Economic status depicted by wealth rank was significantly associated with $4 \mathrm{ANC}$ visit. Various studies have tried to depict economic status by various ways (assets possession, amenity scoring, and income), which have produced difficulty in comparison. However, all the research showed that higher economic status is linked with higher maternal health service utilization (36-39).

Women's knowledge of incentives and health services showed a strong association with women's utilization of ANC service. Women having good knowledge about maternal health services were more than five times more likely to use ANC services compared to those who had poor knowledge. Similarly, mothers having knowledge on incentive upon completion of 4ANC visit were five times more likely to use 4 ANC services than the mothers without such knowledge. Mothers exposed to media were nearly three and half times more likely to complete $4 \mathrm{ANC}$ visit than the mothers not exposed to media, similar to the study in Pakistan and Kenya, which showed an association of media exposure with service utilization (40-42). These findings provide support to the conceptual premise that knowledge and information on service sites and available services made them use the available prenatal services. Improvement of health knowledge is important in Nepal especially among disadvantaged communities for two main reasons. First, pregnancy is considered a natural process, and ANC is still considered a curative service and is sought only when problem arises in South Asian culture $(43,44)$. Second, improving literacy alone is not sufficient to enable them to understand health problem correctly and use proper health services (45). Providing focused and sustained health education through FCHVs, and health workers, therefore, is likely to make women knowledgeable and improve antenatal service utilization (46). A randomized controlled trail conducted in Nepal has previously shown that health education to pregnant women together with their husband was associated with improved health behavior than educating women alone (47).

Women who have faith in traditional healers had less chance of utilizing 4ANC services, which was similar to results from a study conducted in Bangladesh (48). However, it was not clear what proportion of women actually visited traditional healers in their recent pregnancy. Nonetheless, the fact that nearly two-third of current study participants believed in traditional healers' practices indicates deeply embedded social acceptance to indigenous health system in eastern Terai region of Nepal. Nepal's health system recognizes both modern and traditional systems of healing (27). It has been shown in Nepal that faith healers can provide health education in a culturally appropriate and cost-effective manner (49). Against this backdrop, involving faith healers in a productive way to provide health education on maternal and child health seems promising.

Current study did not detect an association of age, education of mother, and parity with utilization of $4 \mathrm{ANC}$ services, which was contrary to the findings of many studies $(14,36,37,50,51)$. Although, characteristics of participants, sampling methods, and other factors might have given rise to unexpected findings, it is interesting to note that socio-cultural factors are more strongly associated with $4 \mathrm{ANC}$ visit in comparison to demographic and biological characteristics.

Information dissemination through different media, mobilization of FCHVs could increase the use of antenatal services. A study conducted in western Nepal showed that nearly $75 \%$ of 
targeted women were reached through direct and indirect exposure to a radio campaign on family planning. Direct exposure to mass media message and indirect interpersonal communication among women showed a synergistic effect on behavior change (52). Policy makers should concentrate on implementing targeted health mass media campaigns through community groups to bring about small-to-moderate effect on behaviors on the basis of growing global evidence (53). Hence, women's empowerment through media campaigns could be a game changer for maternal health service utilization. Along with media campaigns, economic upliftment of women and households will help to ease freedom of movement and remove financial barriers to attend ANC. Women from disadvantaged ethnicities, poor, and marginalized families need additional targeting.

This study attempts to explore socio-cultural barriers to ANC utilization through analysis of socio-economic and demographic characteristics of study population. Although findings from the current study are likely to be subjected to recall bias, it can be considered minimum as we included women who delivered in last 12 months. Nonetheless, some limitations of the present study should be acknowledged. The study was carried out in particular setting of the eastern Terai region, which may not be generalizable to communities from hill or mountain regions; and the cross-sectional nature of the study does not allow the making of inferences regarding temporality of association. Further, sample size for current study was calculated using formulae for measuring proportion considering institutional delivery as the primary outcome. However, the calculated sample size has adequate power ( $>80 \%$ ) to compare many population groups for association with 4ANC coverage. Many studies have highlighted quality of ANC to be a major barrier to utilization of maternal

\section{References}

1. Sundari TK. The untold story: how the health care systems in developing countries contribute to maternal mortality. Int J Health Ser (1992) 22(3):513-28. doi:10.2190/91YH-A52T-AFBB-1LEA

2. Ronsmans C, Graham WJ. Maternal mortality: who, when, where, and why. Lancet (2006) 368(9542):1189-200. doi:10.1016/S0140-6736(06)69380-X

3. World Health Organization. The World Health Report 2005: Make Every Mother and Child Count. Geneva: World Health Organization (2005).

4. World Health Organization. Far More Pregnant Women Getting Antenatal Care. World Health Organization (2004). Available from: http://www.who. int/mediacentre/news/releases/2004/pr22/en/

5. CarroliG,RooneyC, VillarJ.Howeffectiveisantenatalcarein preventingmaternal mortality and serious morbidity? An overview of the evidence. Paediatr Perinat Epidemiol (2001) 15(s1):1-42. doi:10.1046/j.1365-3016.2001.0150s1001.x

6. AbouZahr C, Wardlaw T. Antenatal Care in Developing Countries: Promises, Achievements and Missed Opportunities - An Analysis of Trends, Levels and Differentials, 1990-2001. Geneva: World Health Organization (2003).

7. Campbell OM, Graham WJ, Lancet Maternal Survival Series steering group. Strategies for reducing maternal mortality: getting on with what works. Lancet (2006) 368(9543):1284-99. doi:10.1016/S0140-6736(06)69381-1

8. Paudel D, Shrestha IB, Siebeck M, Rehfuess EA. Neonatal health in Nepal: analysis of absolute and relative inequalities and impact of current efforts to reduce neonatal mortality. BMC Public Health (2013) 13(1):1239. doi:10.1186/ 1471-2458-13-1239

9. Family Health Division. Aama Program Guideline, Second Revision 2069. Kathmandu: Ministry of Health and Population (2012). health care $(28,44)$; however, this study did not investigate supply-side factors.

\section{Conclusion}

Socio-cultural factors including disadvantaged ethnicity, lack of knowledge of services and exposure to information, lower women's autonomy, and belief in traditional healers were identified as barriers to 4ANC service utilization in Sunsari district of eastern Nepal. Lower wealth rank was also identified as a strong barrier to 4ANC service utilization. Taken together, socio-cultural factors and wealth rank showed a stronger association with $4 \mathrm{ANC}$ service utilization in comparison to demographic and biological factors. Hence, removing socio-cultural and economic barriers can increase 4ANC service utilization in eastern Terai region of Nepal.

\section{Author Contributions}

KD designed the research, pre-tested the tool, carried out the field work, and acquired the data. KD, YP, and RK performed the statistical analysis, conducted literature review, and prepared first draft of manuscript. RB, RP, SM, and RW reviewed the manuscript. SM and RRW supervised the project. All the authors read and agreed on the final version of paper.

\section{Acknowledgments}

Authors would like to acknowledge Department of Community Medicine and Public Health, Institute of Medicine, Tribhuwan University, and all the participants who participated in this study.

10. Mehata S, Baral SC, Chand PB, Singh DR, Poudel P, Barnett S. Nepal Household Survey, 2012. Kathmandu: Ministry of Health and Population (2013). 30 p.

11. Powell-Jackson T, Neupane BD, Tiwari S, Tumbahangphe K, Manandhar D, Costello AM. The impact of Nepal's national incentive programme to promote safe delivery in the district of Makwanpur. Adv Health Econ Health Serv Res (2009) 21:221-49.

12. Powell-Jackson T, Hanson K. Financial incentives for maternal health: impact of a national programme in Nepal.JHealth Econ (2012) 31(1):271-84.doi:10.1016/ j.jhealeco.2011.10.010

13. Adhikari SR, Prasai DP, Sharma SK. A Review of Demand side Financing Schemes in the Health Sector in Nepal. Kathmandu: Nepal Health Sector Support Programme (2011). p. 44.

14. Upreti S, Baral S, Tiwari S, Elsey H, Aryal S, Tandan M, et al. Rapid Assessment of the Demand Side Financing Schemes. Kathmandu: Aama Programme and 4 ANC (2012).

15. Hogan MC, Foreman KJ, Naghavi M, Ahn SY, Wang M, Makela SM, et al. Maternal mortality for 181 countries, 1980-2008: a systematic analysis of progress towards millennium development goal 5. Lancet (2010) 375(9726):160923. doi:10.1016/S0140-6736(10)60518-1

16. Pradhan A, Suvedi BK, Barnett S, Sharma SK, Puri M, Poudel P, et al. Nepal Maternal Mortality and Morbidity Study 2008/2009. Kathmandu: Family Health Division, Department of Health Services, Ministry of Health and Population, Government of Nepal (2010).

17. Ministry of Health and Population (MOHP) [Nepal]. New ERA, ICF International Inc. Nepal Demographic and Health Survey 2011. Kathmandu: Ministry of Health and Population, New ERA, and ICF International, Calverton, Maryland (2012). 
18. Pallikadavath S, Foss M, Stones RW. Antenatal care: provision and inequality in rural north India. Soc Sci Med (2004) 59(6):1147-58. doi:10.1016/j.socscimed. 2003.11.045

19. Sharma B. Utilisation of antenatal care services in Nepal. Nepal Popul J (2004) 11(10):79-97.

20. Navaneetham K, Dharmalingam A. Utilization of maternal health care services in Southern India. Soc Sci Med (2002) 55(10):1849-69. doi:10.1016/ S0277-9536(01)00313-6

21. Okolocha C, Chiwuzie J, Braimoh S, Unuigbe J, Olumeko P. Socio-cultural factors in maternal morbidity and mortality: a study of a semi-urban community in southern Nigeria. J Epidemiol Community Health (1998) 52(5):293-7. doi:10.1136/jech.52.5.293

22. Hodge A, Byrne A, Morgan A, Jimenez-Soto E. Utilisation of health services and geography: deconstructing regional differences in barriers to facility-based delivery in Nepal. Matern Child Health J (2014) 19(3):566-77. doi:10.1007/ s10995-014-1540-x

23. Furuta $\mathrm{M}$, Salway $\mathrm{S}$. Women's position within the household as a determinant of maternal health care use in Nepal. Int Fam Plan Perspect (2006) 32(1):17-27. doi:10.1363/3201706

24. Sharma SK, Sawangdee Y, Sirirassamee B. Access to health: women's status and utilization of maternal health services in Nepal. J Biosoc Sci (2007) 39(05):671-92. doi:10.1017/S0021932007001952

25. Simkhada B, Porter MA, Van Teijlingen ER. The role of mothers-in-law in antenatal care decision-making in Nepal: a qualitative study. BMC Pregnancy Childbirth (2010) 10(1):34. doi:10.1186/1471-2393-10-34

26. Matthews SA, Gubhaju B. Contextual Influences on the Use of Antenatal Care in Nepal. Maryland: ORC, Macro Calverton (2004).

27. Pradhan P, Bhattarai S, Paudel I, Gaurav K, Pokharel P. Factors contributing to antenatal care and delivery practices in village development committees of Ilam district, Nepal. Kathmandu Univ Med J (2014) 11(1):60-5. doi:10.3126/ kumj.v11i1.11029

28. Choulagai B, Onta S, Subedi N, Mehata S, Bhandari GP, Poudyal A, et al. Barriers to using skilled birth attendants' services in mid-and far-western Nepal: a cross-sectional study. BMC Int Health Hum Rights (2013) 13(1):49. doi:10.1186/1472-698X-13-49

29. CBS. Nepal Multiple Indicator Cluster Survey 2014: Key Findings. Kathmandu: Central Bureau of Statisctics and Unicef Nepal (2015).

30. CBS. Nepal Living Standard Survey 2010/2011. Statistical Report, Vol. 1. Kathmandu: Central Bureau of Statistics (2011).

31. Ahmed S, Creanga AA, Gillespie DG, Tsui AO. Economic status, education and empowerment: implications for maternal health service utilization in developing countries. PLoS One (2010) 5(6):e11190. doi:10.1371/journal. pone. 0011190

32. Sado L, Spaho A, Hotchkiss DR. The influence of women's empowerment on maternal health care utilization: evidence from Albania. Soc Sci Med (2014) 114:169-77. doi:10.1016/j.socscimed.2014.05.047

33. Malhotra C, Malhotra R, Østbye T, Subramanian SV. Maternal autonomy and child health care utilization in India: results from the national family health survey. Asia Pac J Public Health (2014) 26(4):401-13. doi:10.1177/1010539511420418

34. Chowdhury AMR, Mahbub A, Chowdhury AS. Skilled Attendance at Delivery in Bangladesh: An Ethnographic Study. Dhaka: Research and Evaluation Division, BRAC (2003).

35. Acharya DR, Bell JS, Simkhada P, van Teijlingen ER, Regmi PR. Women's autonomy in household decision-making: a demographic study in Nepal. Reprod Health (2010) 7:15. doi:10.1186/1742-4755-7-15

36. Sathar ZA, Kazi S. Women's Autonomy in the Context of Rural Pakistan. Karachi: The Pakistan Development Review (2000). p. 89-110.

37. Letamo G, Rakgoasi SD. Factors associated with non-use of maternal health services in Botswana. J Health Popul Nutr (2003) 21:40-7.

38. Wagle RR, Sabroe S, Nielsen BB. Socioeconomic and physical distance to the maternity hospital as predictors for place of delivery: an observation study from Nepal. BMC Pregnancy Childbirth (2004) 4(1):8. doi:10.1186/1471-2393-4-8

39. Rashid SF, Hadi A, Afsana K, Begum SA. Acute respiratory infections in rural Bangladesh: cultural understandings, practices and the role of mothers and community health volunteers. Trop Med Int Health (2001) 6(4):249-55. doi:10.1046/j.1365-3156.2001.00702.x

40. Agha S, Carton TW. Determinants of institutional delivery in rural Jhang, Pakistan. Int J Equity Health (2011) 10(1):31. doi:10.1186/1475-9276-10-31

41. Van Eijk AM, Bles HM, Odhiambo F, Ayisi JG, Blokland IE, Rosen DH, et al. Use of antenatal services and delivery care among women in rural western Kenya: a community based survey. Reprod Health (2006) 3(1):2. doi:10.1186/ 1742-4755-3-2

42. Asp G, Pettersson KO, Sandberg J, Kabakyenga J, Agardh A. Associations between mass media exposure and birth preparedness among women in southwestern Uganda: a community-based survey. Global Health Action (2014) 7:22904. doi:10.3402/gha.v7.22904

43. Stephenson R, Tsui AO. Contextual influences on reproductive health service use in Uttar Pradesh, India. Stud Fam Plann (2002) 33(4):309-20. doi:10.1111/ j.1728-4465.2002.00309.x

44. Griffiths P, Stephenson R. Understanding users' perspectives of barriers to maternal health care use in Maharashtra, India. J Biosoc Sci (2001) 33(03):339-59. doi:10.1017/S002193200100339X

45. Patra S, Arokiasamy P, Goli S. Relevance of health knowledge in reporting maternal health complications and use of maternal health care in India. Health Care Women Int (2014) 1-19. doi:10.1080/07399332.2014.946509

46. Ononokpono DN, Odimegwu CO, Imasiku E, Adedini S. Contextual determinants of maternal health care service utilization in Nigeria. Women Health (2013) 53(7):647-68. doi:10.1080/03630242.2013.826319

47. Mullany BC, Becker S, Hindin M. The impact of including husbands in antenatal health education services on maternal health practices in urban Nepal: results from a randomized controlled trial. Health Educ Res (2007) 22(2):166-76. doi:10.1093/her/cyl060

48. Chakraborty N, Islam MA, Chowdhury RI, Bari W, Akhter HH. Determinants of the use of maternal health services in rural Bangladesh. Health Promot Int (2003) 18(4):327-37. doi:10.1093/heapro/dag414

49. WHO. Traditional Practitioners as Primary Health Care Workers. (1995). Available from: http://apps.who.int/medicinedocs/en/d/Jh2941e/5.html

50. Malla DS, Giri K, Karki C, Chaudhary P. Achieving millennium development goals 4 and 5 in Nepal. BJOG (2011) 118(s2):60-8. doi:10.1111/j.1471-0528. 2011.03113.x

51. Joshi C, Torvaldsen S, Hodgson R, Hayen A. Factors associated with the use and quality of antenatal care in Nepal: a population-based study using the demographic and health survey data. BMC Pregnancy Childbirth (2014) 14(1):94. doi:10.1186/1471-2393-14-94

52. Boulay M, Storey JD, Sood S. Indirect exposure to a family planning mass media campaign in Nepal. $J$ Health Commun (2002) 7(5):379-99. doi:10.1080/10810730290001774

53. Noar SM. A 10-year retrospective of research in health mass media campaigns: where do we go from here? J Health Commun (2006) 11(1):21-42. doi:10.1080/10810730500461059

Conflict of Interest Statement: The authors declare that the research was conducted in the absence of any commercial or financial relationships that could be construed as a potential conflict of interest.

Copyright $\odot 2015$ Deo, Paudel, Khatri, Bhaskar, Paudel, Mehata and Wagle. This is an open-access article distributed under the terms of the Creative Commons Attribution License (CC BY). The use, distribution or reproduction in other forums is permitted, provided the original author(s) or licensor are credited and that the original publication in this journal is cited, in accordance with accepted academic practice. No use, distribution or reproduction is permitted which does not comply with these terms. 